\section{Ileus related to wireless capsule retention in suspected Crohn's disease: emergency surgery obviated by early pharmacological treatment}

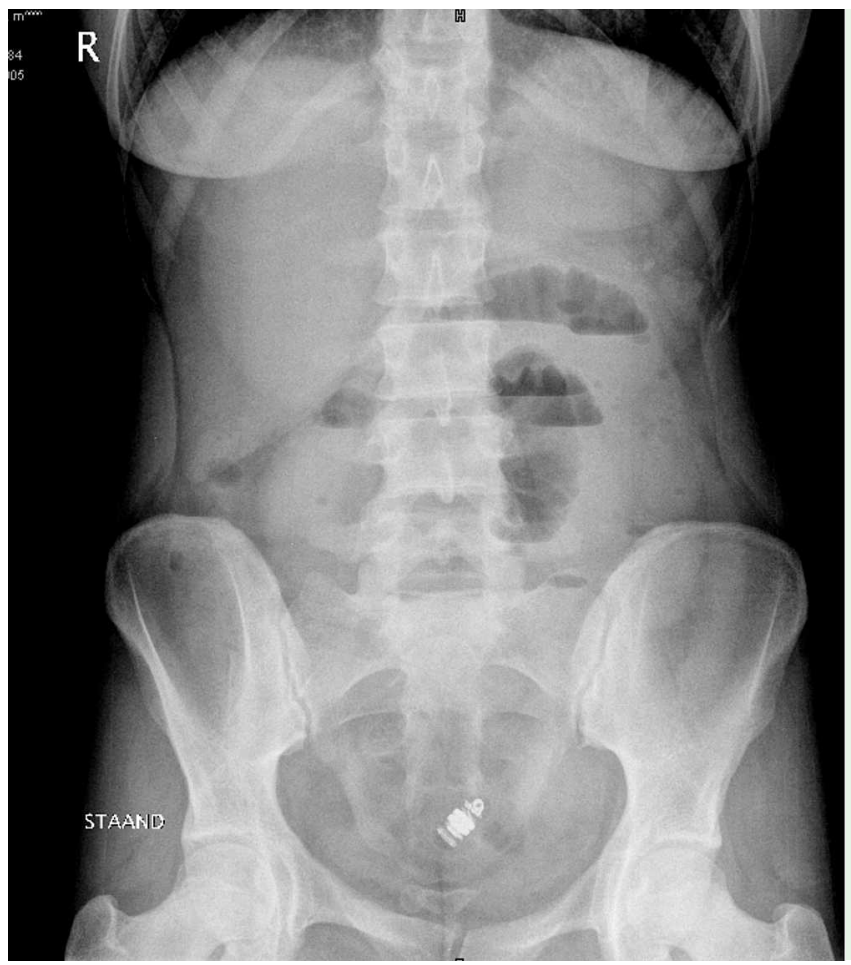

Fig. 1 Upright plain abdominal film approximately 16 hours after capsule ingestion showing multiple airfluid levels, dilated small bowel loops, and the capsule lying centrally in the abdomen.

A previously healthy 21-year-old woman without a history suggesting stenosis and normal ileocolonoscopic findings underwent wireless capsule endoscopy (PillCam SB $11 \times 26 \mathrm{~mm}$; Given Imaging, Yoqneam, Israel) for suspected Crohn's disease of the small bowel. Approximately 16 hours after capsule intake, she developed small-bowel ileus ( $\bullet$ Fig. 1). The capsule recording showed skip lesions of inflamed small bowel with ulcerations, swelling, pseudopolyps, and stenosis (๑ Fig. 2). After 6.5 hours, capsule progression was halted by a strictured small-bowel segment with severely active disease ( Fig. 3). A diagnosis of severe stenosing Crohn's disease of the small bowel with subsequent capsule retention leading to obstruction of the small bowel was made.

After consultation with the surgeons it was decided to try to induce reduction of the swelling and stenosis medically. Three hours after onset of symptoms, $200 \mathrm{mg}$ hydrocortisone and $300 \mathrm{mg}$ infliximab were administered. Six hours later the patient felt much better. A new abdominal exam indicated that the capsule had progressed into the sigmoid colon ( $\bullet$ Fig. 4). Capsule endoscopy has rapidly become the procedure of choice for evaluation of suspected small-bowel Crohn's disease because of its safety and high diagnostic yield, in particular when ileocolonoscopy is negative [1]. Capsule retention proximal to a stenosis is the most important complication but is rare $[2,3]$. Treatment usually consists of endoscopic or surgical intervention with simultaneous treatment of the stenosis. If a stenosis is suspected, small-bowel radiography has to be done first $[3,4]$. Alternatively, the "patency" capsule may be used, but reports on its efficacy are equivocal [5].

We conclude that immediate treatment with immunosuppressive medication to reduce swelling and stenosis should be considered in acute cases of capsule retention if a diagnosis of Crohn's disease can be established on the basis of the images made by the obstructing capsule. In this way surgery can be avoided or at least postponed, and at the same time treatment of the underlying disease is initiated.

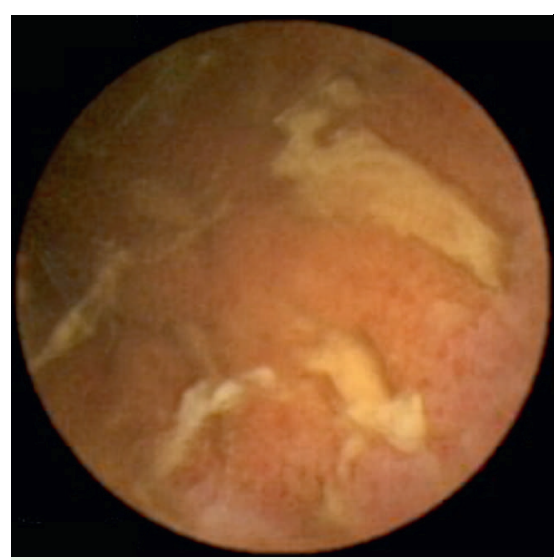

Fig. 2 Wireless capsule image made 3 hours 7 minutes after capsule ingestion: ulcerations and erythema are noticed for the first time.
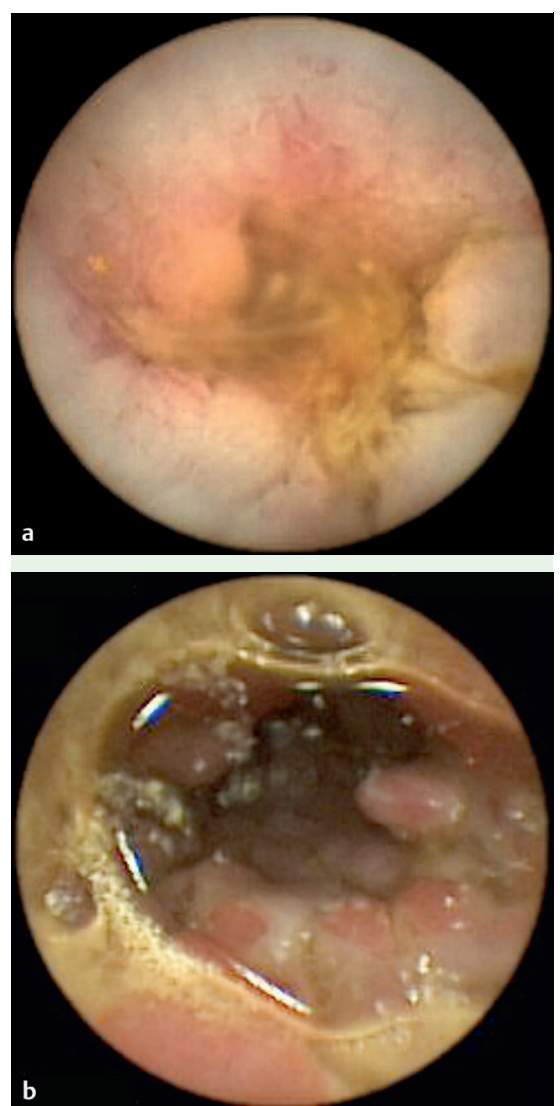

Fig. 3 a, b Wireless capsule images made 6 hours 40 minutes and 6 hours 49 minutes after capsule ingestion, showing a narrowed smallbowel segment with swelling, ulceration, and pseudopolyps. The capsule seems to be tumbling backward and forward in the same severely diseased and narrowed bowel segment in the distal jejunum. The locating software suggested the location of the stenosing segment in the distal jejunum.

Endoscopy_UCTN_Code_CPL_1AI_2AB 


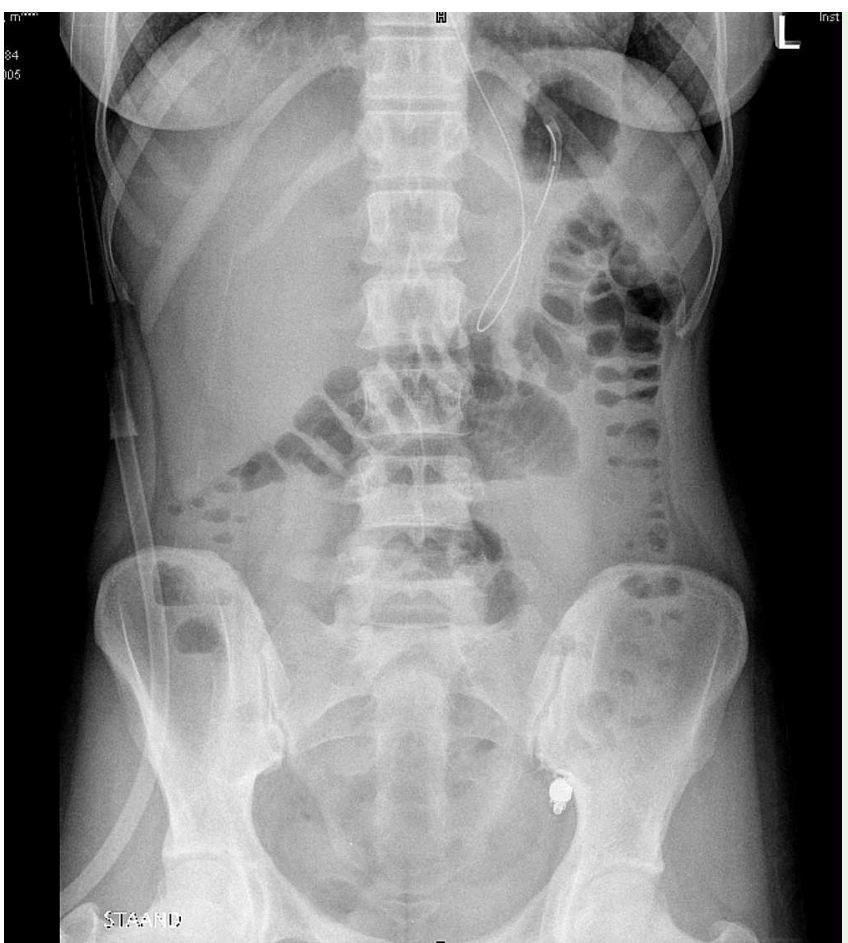

Fig. 4 Upright plain abdominal film showing wireless capsule in the sigmoid.

\section{Vanfleteren, P. van der Schaar, J. Goedhard}

Department of Gastroenterology and Hepatology, Atrium Medical Center, Heerlen, The Netherlands

\section{References}

1 Fidder HH, Nadler M, Lahat $A$. The utility of capsule endoscopy in the diagnosis of Crohn's disease based on patient's symptoms. J Clin Gastroenterol 2007; 41: $384-$ 387
2 Rondonotti E, Herrerias JM, Pennazio $M$ et al. Complications, limitations, and failures of capsule endoscopy: a review of 733 cases. Gastrointest Endosc 2005; 62: 712 - 716

3 Cheifetz AS, Kornbluth AA, Legnani P. The risk of retention of the capsule endoscope in patients with known or suspected Crohn's disease. Am J Gastroenterol 2006; 101: 2218 2222

4 Voderholzer WA. The role of PillCam endoscopy in Crohn's disease: the European experience. Gastrointest Endosc Clin N Am 2006; 16: $287-297$

5 Delvaux M, Ben Soussan E, Laurent $V$ et al. Clinical evaluation of the use of the M2A patency capsule system before a capsule endoscopy procedure, in patients with known or suspected intestinal stenosis. Endoscopy 2005; 37: $801-807$

\section{Bibliography}

DOI $10.1055 / \mathrm{s}-0029-1214664$

Endoscopy 2009; 41: E134-E135

(c) Georg Thieme Verlag KG Stuttgart · New York . ISSN 0013-726X

\section{Corresponding author}

\section{Vanfleteren, MD}

Department of Gastroenterology and Hepatology Atrium Medical Center

Henry Dunant straat 5

Postbus 4446

6401 CX Heerlen

The Netherlands

lowievanfleteren@gmail.com 